\title{
Software livre para gerenciamento de eventos: uso e apropriação por uma instituição pública de ensino
}

\author{
Sônia Miranda de Oliveira \\ Centro Federal de Educação Tecnológica de Minas Gerais \\ somioli2@yahoo.com.br \\ Leila Marli de Lima Caeiro \\ Centro Federal de Educação Tecnológica de Minas Gerais \\ leila.caeiro@gmail.com
}

\section{Como citar:}

OLIVEIRA, S. M. de; CAEIRO, L. M. de L. Software livre para gerenciamento de eventos: uso e apropriação por uma instituição pública de ensino. In: ABEC MEETING, 2, 2018, São Paulo. Anais... São Paulo: Associação Brasileira de Editores Científicos, 2018. p. 1-6.

http://dx.doi.org/10.21452/abecmeeting.2018.173

\section{RESUMO}

A proposta deste trabalho consiste em um estudo de caso da experiência no uso de um software livre para gerenciamento de eventos. O Sistema Online de Acompanhamento de Conferências (SOAC), que é uma adequação do Open Conference System (OCS), foi implantado no Centro Federal de Educação Tecnológica de Minas Gerais - CEFET-MG em 2012. Desde então, 32 eventos foram gerenciados por meio desta plataforma e um resultado bastante animador foi que um desses eventos, teve seus melhores trabalhos selecionados para compor um periódico científico. Nesse sentido, entendemos o portal como uma ferramenta de divulgação científica e repositório institucional de eventos.

Palavras-chave: Divulgação científica. SOAC. Eventos acadêmicos. CEFET-MG

\section{ABSTRACT}

The proposal of this work consists of a case study of the experience in the use of free software for event management. The Online Conference Monitoring System (SOAC), which is an adaptation of the Open Conference System (OCS), was implemented in the Federal Center for Technological Education of Minas Gerais - CEFET-MG in 2012. Since then, 32 events have been managed through of this platform and a very encouraging result was that one of these events had his best works selected to compose a scientific journal. In this sense, we understand the portal as a tool to disseminate academic production and institutional repository of events.

Keywords: Scientific divulgation. SOAC. Academic events. CEFET-MG 


\section{CONSIDERAÇÕES INICIAIS}

O uso de um software livre para gerenciamento de eventos configura-se como uma ferramenta que facilita a implantação, divulgação e gerenciamento de atividades no espaço acadêmico. O Sistema Online de Acompanhamento de Conferências (SOAC) permite que todas as etapas e trâmites vinculados à organização de um evento sejam administrados. Trata-se, portanto, de uma importante ferramenta para implementação de portais que podem abrigar sites de eventos.

Em 2012, no Centro Federal de Educação Tecnológica (CEFET) de Minas Gerais (MG), por meio da Coordenação Geral de Divulgação Científica, vinculada à Diretoria de Pesquisa e Pós-graduação (DPPG), iniciou-se a utilização do portal SOAC para organização de eventos. A iniciativa visou reunir e possibilitar o gerenciamento eletrônico dos diversos eventos acadêmicos promovidos e realizados no âmbito da Instituição. O Portal funcionaria, ainda, como repositório e guarda da produção científica gerada. Outro benefício do portal seria o fator de contribuir, efetivamente para a promoção, divulgação e disseminação do conhecimento técnico-científico produzido na instituição.

\section{SOBRE O SISTEMA ONLINE DE ADMINISTRAÇÃO DE CONFERÊNCIAS (SOAC)}

De acordo com a cartilha de utilização do SOAC é uma tradução do Open Conference System (OCS). O OCS que chegou ao Brasil em 2003, por meio do Instituto Brasileiro de Informação em Ciência e Tecnologia (Ibict), foi utilizado para organizar a VIII Internacional Conference on Eletronic Publishing (ELPUB) e desde então, tornou-se ferramenta para organização de vários eventos nacionais e internacionais. Trata-se de um software livre, com código aberto, desenvolvido para criação de portais institucionais para abrigar sites de eventos. O software permite a criação e a edição desses sites, ou seja, todo o gerenciamento de eventos, desde as chamadas, inscrição, pagamento, publicação de anais eletrônicos, coleta dos metadados por provedores de serviço e possibilita a busca e navegação por autor e título de todos os artigos nele cadastrados.

O SOAC/OCS possui um histórico semelhante ao software Open Journal System (OJS), sendo uma adaptação deste e, nesse sentido, ambos são mantidos pelo Public Knowledge Project (PKP) localizada na University of British Columbi no Canadá. Em 2010 o Ibict e a PKP, via Universidade Stanford, firmaram um memorando de entendimento, pelo qual, se comprometiam a estabelecer competências de forma colaborativa. Assim, o Ibict torna-se parceiro do PKP, com relação às ferramentas desenvolvidas por essa entidade.

O SOAC foi projetado para reduzir o tempo e energia que são dedicados às tarefas técnicas e administrativas associadas ao controle de um evento, visando melhorar a eficiência dos processos editoriais. Segundo Ibict (2011, online) o SOAC "É uma ferramenta livre de publicação na Web que proporciona um ambiente completo para a gestão de conferências científicas".

Amparados nos movimentos de acesso aberto e arquivos abertos, o SOAC, possui facilidades de acesso aos anais, com ferramenta de busca e navegação por autor e título. Da mesma forma, possibilita a coleta dos metadados por provedores de serviço, que permite que os anais possam ser indexados por outros serviços. 
Por tantos motivos, o SOAC apresenta-se como um sistema único no propósito de apoiar a criação de portais de eventos acadêmicos. Agregando em uma única iniciativa todas as ocorrências e edições, de eventos apoiados por uma instituição, racionalizando esforços e oferecendo facilidades a instituição.

O programa permite, ainda, acompanhar as diversas etapas da organização de eventos acadêmicos. Destaca-se, portanto, como uma ferramenta que oferece uma variedade de uso, incluindo facilitadores relacionados aos processos de avaliação, que envolvem o credenciamento de avaliadores, moderadores, fluxo da avaliação, formulários para avaliação e outros. O SOAC facilita o acesso aos anais dos eventos com ferramentas de busca e navegação por autor e título. Dessa forma, a coleta dos metadados podem ser feitas por provedores de serviço, permitindo ainda, que os anais sejam indexados por outros serviços.

Em síntese o SOAC possibilita (SHINTAKU; BRITO; FLEURY, 2014, p. 8):

- compor e enviar chamadas de trabalhos;

- aceitar artigos e submissões de resumos eletronicamente;

- permitir a autores editar e revisar trabalhos enviados;

- publicar anais de conferências e trabalhos em um formato pes- quisável;

- enviar e-mails;

- registrar participantes;

- integrar discussões on-line pós-conferência.

Segundo Shintaku; Brito e Fleury (2014, p. 11)

O esquema mais amplo para o qual o sistema foi planejado consiste em um portal institucional, a partir do qual são criadas as conferências. Cada conferência possui suas edições, sobre as quais ocorrem a chamada e o envio de trabalhos, o registro de participantes, a publicação de anais, entre outras ações típicas de congressos ou eventos acadêmicos.

\section{IMPLANTAÇÃO DO SOAC NO CEFET-MG}

No ano de 2012 decidiu-se pela implantação do Portal de Conferências do CEFET-MG, utilizando-se o software SOAC como gerenciador. Já neste primeiro ano, a primeira conferência, a se utilizar deste sistema para gerenciar todas as etapas administrativas do evento, a VIII Semana Nacional de Ciência e Tecnologia do CEFETMG, contou com 276 trabalhos inscritos, tendo aprovado 234 trabalhos após avaliação cega de avaliadores cadastrados, e rejeitado 42, que não estavam de acordo com as normas regulamentares do evento.

No quadro 1 são listados todos os eventos que compõem o Portal de Conferências do CEFET-MG, ordenados por ano. 
OLIVEIRA, S. M. de; CAEIRO, L. M. de L.

"Software livre para gerenciamento de eventos: uso e apropriação por uma instituição pública de ensino"

Quadro 1 - Eventos gerenciados pelo SOAC - Portal de Conferências do CEFET-MG.

\begin{tabular}{|c|c|c|}
\hline Item & Nome da Conferência & Ano \\
\hline 1. & VIII Semana de Ciência \& Tecnologia 2012 - CEFET-MG & 2012 \\
\hline 2. & IX Semana de Ciência \& Tecnologia 2013 - CEFET-MG & 2013 \\
\hline 3. & XXIII Mostra Específica de Trabalhos e Aplicações 2013 - META & 2013 \\
\hline 4. & $\begin{array}{l}\text { Seminário de Trabalhos Técnico-Científicos dos Servidores TAE em } \\
\text { Gestão Pública - } 2013\end{array}$ & 2013 \\
\hline 5. & $\begin{array}{l}\text { Seminário de Discentes dos Programas de Pós - Graduação Stricto Sensu } \\
-2013\end{array}$ & 2013 \\
\hline 6. & V Encontro Mineiro de Análise do Discurso & 2014 \\
\hline 7. & X Semana de Ciência \& Tecnologia 2014 - CEFET-MG & 2014 \\
\hline 8. & Diálogos: Ensinar Ciências na Educação Básica e Profissional & 2014 \\
\hline 9. & II Seminário de Trabalhos Técnicos - Científicos dos Servidores TAE & 2014 \\
\hline 10. & $\begin{array}{l}\text { Seminário de Discentes dos Programas de Pós - Graduação Stricto Sensu } \\
\text { - } 2014\end{array}$ & 2014 \\
\hline 11. & Química 50 anos & 2014 \\
\hline 12. & Ciência e Tecnologia para a Sustentabilidade Ambiental & 2014 \\
\hline 13. & XI Semana de Ciência \& Tecnologia 2015 - CEFET-MG & 2015 \\
\hline 14. & $\begin{array}{l}\text { Seminário de Discentes dos Programas de Pós - Graduação Stricto Sensu } \\
-2015\end{array}$ & 2015 \\
\hline 15. & Diálogos 2015: Ensinar Ciências na Educação Básica e Profissional & 2015 \\
\hline 16. & $1^{\text {a }}$ Semana de Reciclagem, Recuperação e Reutilização de Materiais & 2016 \\
\hline 17. & $12^{\mathrm{a}}$ Semana de Ciência \& Tecnologia 2016 - CEFET-MG & 2016 \\
\hline 18. & $26^{a}$ Mostra Especifica de Trabalhos e Aplicações & 2016 \\
\hline 19. & Diálogos 2016 & 2016 \\
\hline 20. & 19o Congresso Brasileiro de Catálise & 2017 \\
\hline 21. & $\begin{array}{l}\text { Seminário de Discentes dos Programas de Pós-Graduação Stricto Sensu - } \\
2017\end{array}$ & 2017 \\
\hline 22. & XIX CECEMM & 2017 \\
\hline 23. & Seminário Científico Libras na Escola e na Vida & 2017 \\
\hline 24. & Jornada de Linguagens, Tecnologia e Ensino & 2017 \\
\hline 25. & 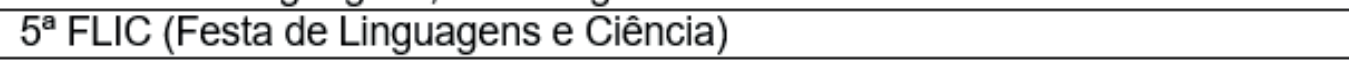 & 2017 \\
\hline 26. & $27^{\text {a }}$ Mostra Específica de Trabalhos e Aplicações & 2017 \\
\hline 27. & 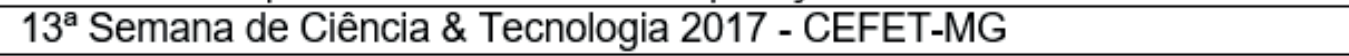 & 2017 \\
\hline 28. & VII Workshop - Mestrado em Engenharia da Energia & 2017 \\
\hline 29. & 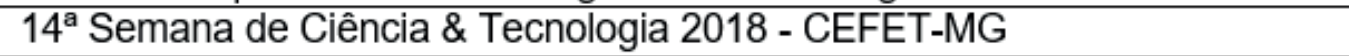 & 2018 \\
\hline 30. & $28^{\mathrm{a}}$ META 2018 - CEFET-MG & 2018 \\
\hline 31. & Seminário de Discentes dos Programas de Pós-Graduação Stricto Sensu & 2018 \\
\hline 32. & I MOSTRA DE EXTENSÄO DO CEFET-MG & 2018 \\
\hline
\end{tabular}

Fonte: Portal de Conferências do CEFET-MG, 2018.

Nos anos seguintes a utilização do SOAC, como gerenciador dos eventos do CEFET-MG consolidou-se. Atualmente o Portal de Conferências do CEFET-MG conta com 32 eventos cadastrados e podem ser consultados on-line através de sua página.

No ano de 2017 foram gerenciados via SOAC 10 eventos, tendo a 13 a Semana de Ciência e Tecnologia do CEFET-MG recebido 480 inscrições e aprovado 421 trabalhos para apresentação. No caso da 27a Mostra Específica de Trabalhos e Aplicações META do CEFET-MG foram feitas 461 inscrições e foram apresentados 395 trabalhos.

Em 2017 foi estabelecida a reativação da Revista da META e os melhores trabalhos apresentados nas 10 unidades do CEFET-MG foram transformados em artigos científicos e compuseram o primeiro número eletrônico da revista. Seguindo 
a política de utilização de softwares livres, o CEFET-MG usa o sistema SEER para gerenciar o Portal de Periódicos do CEFET-MG.

O Portal de Periódicos do CEFET-MG é gerenciado pela Coordenação Geral de Divulgação Científica e Tecnológica (CGDCT) do CEFET-MG que visa reunir em um único ambiente digital as revistas científicas produzidas na instituição. O Portal de Periódicos do CEFET-MG utiliza o Sistema Eletrônico de Editoração de Revistas (SEER), software desenvolvido pela equipe do Public Knowledge Project. O SEER foi traduzido e adaptado pelo Ibict, a partir do OJS, e inclui recursos, estratégias e metodologias essenciais às atividades de editoração de periódicos científicos em ambiente digital.

O sistema SEER oferece ampla visibilidade e acessibilidade aos conteúdos dos artigos, além de todos os recursos necessários à gestão e manutenção dessas revistas, otimizando, significativamente, o trabalho de seus editores.

A reunião de todas as revistas em um único endereço digital, cujas tecnologias utilizadas se fundamentam na filosofia do acesso aberto e no modelo de arquivos abertos, é de suma relevância para a comunidade acadêmica e para a sociedade em geral, ambas em nível global. Mais que isso, a transparência permitida pelo acesso amplo e irrestrito aos seus conteúdos não deixa de constituir um retorno da Universidade à sociedade. (GUIMARÃES; FREITAS, 2010, p. 7).

A ideia de disponibilizar a Revista da META nesta plataforma, além de divulgar a produção científica gerada pelos alunos, com os melhores trabalhos apresentados, pretende também, estimular professores e alunos a aperfeiçoarem e diversificarem seus trabalhos, visando a possibilidade de publicação. O circulo vicioso que se cria é necessário e benéfico para a instituição, que vê ampliada a gama de pesquisas e grupos interessados em produzir e divulgar conhecimento.

O primeiro número da Revista da META, com acesso via Portal de Periódicos do CEFET-MG , contou com mais de 70 artigos das 10 Unidades da instituição e o resultado foi muito produtivo. O envolvimento de alunos e docentes para produzirem mais e melhores trabalhos ficou perceptível. O objetivo de terem seus artigos publicados em um periódico científico e disponibilizados em um portal com acesso on-line é muito motivador.

O Portal de Periódicos do CEFET-MG está sendo melhorado e outras revistas científicas estão sendo organizadas para fazerem parte dele.

\section{CONSIDERAÇÕES CONCLUSIVAS}

O SOAC pode ser interpretado como uma ferramenta que contribui para a disseminação dos eventos acadêmicos e com isso desponta-se como um facilitador da divulgação científica. Dessa forma, os eventos e acontecimentos acadêmicos (conferências, congressos, encontros, seminários e outros), podem ser compartilhados via $w e b$, revelando um potencial tecnológico de comunicação científica.

No Centro Federal de Educação Tecnológica de Minas Gerais - CEFET-MG, com a utilização do SOAC pôde-se perceber a potencialidade desta ferramenta. Assim, desde 2012, 32 eventos foram administrados por meio da plataforma do SOAC. O que buscou-se destacar neste artigo foi que a partir de eventos bem organizados e gerenciados é possível estimular e promover a produção científica e acadêmica de uma instituição. Na META, os trabalhos com destaque foram selecionados para compor um 
"Software livre para gerenciamento de eventos: uso e apropriação por uma instituição pública de ensino"

periódico. Dessa forma, entendemos a importância do portal de conferências, tanto para a administração dos eventos quanto para a transformação do que é desenvolvido nesses eventos em produtos acadêmicos. Salientamos com isso, a necessidade na manutenção e na ampliação do uso de tal ferramenta nos âmbitos da Instituição.

\section{REFERÊNCIAS}

GUIMARÃES, L.; FREITAS, M. A. de. Guia para editores de periódicos da Universidade de Brasília. Brasília: UNB, 2010.

BRASIL. CENTRO FEDERAL DE EDUCAÇÃO TECNOLÓGICA. Portal de conferências do CEFET-MG. Belo Horizonte: CEFET-MG, 2018. Disponível em: <https://www. conferencias.cefetmg.br>. Acesso em 28 jun. 2018.

CENTRO FEDERAL DE EDUCAÇÃO TECNOLÓGICA. Portal de periódicos do CEFET-MG. Belo Horizonte: CEFET-MG, 2018. Disponível em: <https://www. periodicos.cefetmg.br/>. Acesso em: 28 jun. 2018.

SHINTAKU, M.; BRITO, R. F. de; FLEURY, A. SOAC/OCS para gerentes gerais. Brasília: IBICT, 2014. Disponível em: <http://labcoat.ibict.br/portal/wp-content/ uploads/2015/03/Item-12-Digital-2.pdf>. Acesso em: 20 jun. 2018. 